\title{
Chitosan and Agaricus brasiliensis Polysaccharides Films: A Preliminary Study
}

\author{
Maria L. C. Gonzaga, ${ }^{a}$ Matheus S. Campelo, ${ }^{a}$ Katarina B. Saraiva, ${ }^{a}$ Alan Q. S. Santos, ${ }^{a}$ \\ Luzia K. A. M. Leal, ${ }^{b}$ Nágila M. P. S. Ricardo, ${ }^{a}$ Sandra A. Soares ${ }^{a}$ and \\ Maria Elenir N. P. Ribeiro ${ }^{\circledR} *, a$
}

\author{
${ }^{a}$ Laboratório de Polímeros e Inovação de Materiais, Departamento de Química Orgânica e Inorgânica, \\ Universidade Federal do Ceará, 60455-760 Fortaleza-CE, Brazil \\ ${ }^{b}$ Departamento de Farmácia, Universidade Federal do Ceará, Campus do Porangabuçu, \\ 60430-170 Fortaleza-CE, Brazil
}

\begin{abstract}
The known biotechnological properties of chitosan and the recent biological activities attributed to polysaccharides from Agaricus brasiliensis have been of interest to obtain films constituted by these two polymers. The glucans obtained from the mushroom inhibited about $96.5 \%$ of the ferrous ion, besides not promoting a significant increase of lactate dehydrogenase enzyme (LDH), which indicates that the polysaccharide is able to inhibit the production of radical species and also presents low cytotoxicity to the biological systems. The results of spectroscopy analyses in the infrared region (FTIR) and X-ray diffraction suggest an existing electrostatic interaction between the substances. A reduction in the films' swelling capacity was observed with an increase in the polysaccharide content in the composition. In addition, scanning electron microscopy (SEM) revealed greater surface density of the films. In convening the biological properties of the substances, it is expected that this study raises interest in evaluating the films and their capacity for healing wounds and burns.
\end{abstract}

Keywords: films, chitosan, Agaricus brasiliensis polysaccharides

\section{Introduction}

The use of films based on biopolymers in food packaging, wound covering and drug permeation systems have gained prominence in recent decades. ${ }^{1-3}$ This fact is associated with their different biological properties, such as antimicrobial and antioxidant activity, wound healing and hemocompatibility. ${ }^{4-7}$ Furthermore, they form biodegradable films with good mechanical characteristics, which would allow them to replace synthetic polymers. ${ }^{8}$

Chitosan is one of the most studied polymers. Its polymeric chain consists of glucosamine and $\mathrm{N}$-acetyl glucosamine monomers, obtained by the deacetylation of chitin, the second most abundant polysaccharide in nature. Its use in films intended for wound healing can be justified because it is a biodegradable, non-toxic and biocompatible polymer and presents many biological activities. On the other hand, it has free amino groups capable of attacking electrophilic centers or interacting electrostatically with negatively charged groups in the acid medium forming crosslinks. $^{9-13}$

*e-mail: elenir.ribeiro@ufc.br
The isolation and characterization method of polysaccharides isolated from the Agaricus brasiliensis mushroom are composed of glucans bound in configurations $\beta(1 \rightarrow 6)$ and $\alpha(1 \rightarrow 4)$, either free or in association with proteins, forming proteoglycans. ${ }^{14}$ These macromolecules have presented many therapeutic properties such as analgesic, antitumor, immunomodulatory and antiherpetic activities. $^{14-18}$

Thus, it is estimated that the interaction between chitosan and polysaccharides isolated from the Agaricus brasiliensis mushroom is electrostatic, occurring between the carboxylate groups present in the proteoglycan complex and the amino group of chitosan. This interaction is already reported in the literature ${ }^{19}$ for polymeric blends between chitosan and gelatin under appropriate $\mathrm{pH}$ conditions. In addition, it has been employed to obtain films by the layer-by-layer method, as in the studies by other authors..$^{20,21}$

Films have been obtained with a mixture of at least two polymers or copolymers, without having any reaction between them most of the time. ${ }^{22-24}$ In parallel, the occurrence of intermolecular interactions between the monomers of the employed polymers guarantees 
a polymeric matrix that is capable of incorporating drugs and to promote their permeation and controlled release. ${ }^{25-28}$

Films constituted of chitosan/cellulose/polyvinyl alcohol, chitosan/starch/halloysite nanotubes, chitosan/Aloe vera, and chitosan/collagen have been extensively studied. ${ }^{29-32}$ Most of the studies are aimed at improving the physical, physicochemical properties and the processing of the materials compared with the properties of isolated polymers.

The objective of the present work is to prepare and characterize chitosan films and polysaccharides isolated from the Agaricus brasiliensis mushroom as a potential alternative for cutaneous drug permeation and wound treatment.

\section{Experimental}

Chitosan used in the study presented a deacetylation degree around $85.81 \%$. The Agaricus brasiliensis mushroom was supplied by GUINISHI Commerce of Import and Export of Nourishment Products LTD, Suzano, São Paulo, Brazil. Polysaccharides were isolated according to Gonzaga et al., ${ }^{33}$ using the following method: $10 \mathrm{~g}$ of dried and sprayed mushroom was suspended in $5 \%\left(\mathrm{~m} \mathrm{~m}^{-1}\right)$ distilled water at $100{ }^{\circ} \mathrm{C}$ under stirring for $5 \mathrm{~h}$. After this period, the suspension was vacuum filtered and then centrifuged to obtain the extract. The filtrate was neutralized to $\mathrm{pH} 7.0$ by addition of diluted $\mathrm{NaOH}$ solution. $\mathrm{NaCl}\left(1.0 \% \mathrm{~m} \mathrm{v}^{-1}\right)$ was added to the filtrate (where $\mathrm{m}$ is the mass of $\mathrm{NaCl}$ and $\mathrm{v}$ the volume of the extract) to induce subsequent precipitation of the polysaccharides in ethanol. Ethanol/solution was added to the extract, 5:1, to obtain the precipitates, which were isolated from the ethanolic medium by centrifugation, washed with acetone and dried. Hydrogen peroxide (30\%) was used as a 1:1 ethanol/ peroxide mixture for approximately $15 \mathrm{~h}$, at ambient temperature for the clarification of the extracted material. The materials were submitted to a second extraction using ethanol/volume of the extract ( $4: 1)$ due to its partial solubilization.

The precipitate was isolated by centrifugation, washed with ethanol, then washed with acetone and dried in a sand bath at $40{ }^{\circ} \mathrm{C}$. The isolated material was dissolved in distilled water with stirring at $40{ }^{\circ} \mathrm{C}$ for $48 \mathrm{~h}$ to purify the sample from possible insoluble substance. After this procedure, the suspension was centrifuged, and the soluble phase was removed and submitted to lyophilization.

\section{Ferrous ion chelating assay}

The assay was based on Chew et al. ${ }^{34}$ with some modifications. An aliquot of $1.0 \mathrm{~mL}$ of polysaccharide solution $\left(0.5,1.0,2.0\right.$ or $\left.3.0 \mathrm{mg} \mathrm{mL}^{-1}\right)$ or the standard solution was mixed with $1.0 \mathrm{~mL}$ of $0.1 \mathrm{mM} \mathrm{FeSO}_{4}$ and $1.0 \mathrm{~mL}$ of $0.25 \mathrm{mM}$ ferrozine. The mixtures (in triplicates) were incubated at $25{ }^{\circ} \mathrm{C}$ for $10 \mathrm{~min}$. Absorbance (A) was measured at $562 \mathrm{~nm}$. A calibration curve was made with ethylenediamine tetraacetic acid (EDTA) as standard (30-60 $\mu \mathrm{g} \mathrm{mL}^{-1}$ ). The result was expressed in percentage of ferrous ion chelating ability using equation 1 :

Ferrous ion chelating ability $(\%)=\left[\left(\mathrm{A}_{\text {control }}-\mathrm{A}_{\text {sample }}\right) /\right.$

$\left.\mathrm{A}_{\text {control }}\right] \times 100$

\section{Cytotoxicity study}

Human neutrophils were isolated by the method of Lucisano and Mantovani ${ }^{35}$ with some modifications. ${ }^{36}$ Cell pellets were suspended in Hank's balanced salt solution (HBSS) containing 80-90\% neutrophils with viability of $90 \pm 2.0 \%$ established by a Trypan Blue exclusion test. Human neutrophils $\left(2.5 \times 10^{6}\right.$ cells $\left.\mathrm{mL}^{-1}\right)$ were incubated (15 min at $37^{\circ} \mathrm{C}$ ) with HBSS (non-treated cells), Triton X-100 $\left(0.2 \%\left(\mathrm{v} \mathrm{v}^{-1}\right)\right.$, standard cytotoxic), and polysaccharides were isolated from Agaricus brasiliensis mushroom samples (1.0, 10.0, 25.0, 50.0, 100.0 $\left.\mu \mathrm{g} \mathrm{mL}^{-1}\right)$. The lactate dehydrogenase (LDH) activity was determined by a commercially available method (LDH liquiform of Labtest Diagnosis).

\section{Film preparation}

Polysaccharides isolated from the mushroom did not form films when tested alone. Therefore, it was decided to formulate blends with chitosan and proteoglycans. Chitosan (Qt) mass and proteoglycans (PC) mass were individually solubilized in $1 \%$ acetic acid and then mixed with light stirring and heating $\left(45^{\circ} \mathrm{C}\right)$. Qt and $\mathrm{PC}$ masses were utilized for obtaining films in the following compositions: Qt, PC/Qt 1:3, 1:5 and 1:7. The resultant mixtures of the established compositions were filtered in funnels with sintered plates by vacuum, deposited in Petri plates (13.0 cm of diameter, $1.0 \mathrm{~cm}$ height) and left at room temperature for 3 days to evaporate the solvent.

After the films were obtained, they were treated with $3.0 \mathrm{~mol} \mathrm{~L}{ }^{-1} \mathrm{NaOH}$ solution for $2 \mathrm{~h}$ and then washed with distilled water until they reach neutral $\mathrm{pH}$. The base treatment has the objective to shield from the present charges, transforming the insoluble films into water, as well as removing the residual acetic acid. In the drying process, the films were then left in Petri plates to dry at room temperature for approximately $48 \mathrm{~h}$. The materials were duly protected during the solvent evaporation and drying stages to prevent them from being contaminated. 


\section{Films characterization}

\section{Film thickness and solubility}

After drying, the thickness of the films was determined using a Check Line DCF 900 USA digital micrometer. The solubility of the films was tested in water, basic medium $(3 \% \mathrm{NaOH})$, acidic medium $\left(1 \% \mathrm{CH}_{3} \mathrm{COOH}\right)$, ethanol and acetone. The solubility test was performed according to a methodology proposed by Mi et al. ${ }^{37}$ with modifications.

\section{Swelling procedures}

The difference between the film thickness ( $\mathrm{T}$ ) and an evaluation of the swelling capacity was achieved through the difference between the thickness measurements of the dry films after $12 \mathrm{~h}$ of immersion in distilled water, according to equation 2 . The measurements were achieved using a Check Line DCF 900 USA digital micrometer. Thickness was evaluated at ten different film regions.

Swelling capacity $=\left(\mathrm{T}_{\text {swelled films }}-\mathrm{T}_{\text {dry films }}\right)$

\section{Infrared spectroscopy}

Fourier-transform infrared spectroscopy (FTIR) spectra were recorded to study the structure of the polysaccharide components of the films and eventual interactions between them. The films were analyzed using a Shimadzu IR spectrophotometer (model 8300) by attenuated total reflectance (ATR) between 4000 and $400 \mathrm{~cm}^{-1}$ with 32 scans. The experiment was carried out twice.

\section{X-ray diffraction}

Films (Qt and PC/Qt) and the polysaccharide powder were analyzed in an X'Pert PRO Philips Diffractometer. The scans were achieved in angle intervals spreading $2 \theta$ of 5 to $40^{\circ}$, with steps of $0.5^{\circ} \mathrm{min}^{-1}$, with a copper tube being operated at a voltage of $40 \mathrm{kV}$ and currents of $25 \mathrm{~mA}$.

\section{Scanning electron microscopy (SEM)}

The morphology of the films was studied through micrographs obtained in a Phillips XL 30 equipment. This study has the intention to evaluate the interaction of the mushroom polysaccharides with the chitosan molecules. The micrographs were obtained at $10.0 \mathrm{kV}$ and magnification of 2000 times.

\section{Permeation procedures of the drugs}

The thickness of the films were first measured before and after $12 \mathrm{~h}$ of hydration. Ten measures of each film were tested, using a digital micrometer. The permeation experiments were achieved in a controlled bath at $30 \pm 0.1^{\circ} \mathrm{C}$, using a system composed of two cylinders upon which the humid films were individually fixed. The purpose of this fixation is to avoid the time delay, as described in the literature, ${ }^{38,39}$ defined as the necessary time to complete the film swelling and conferring stability to the system. For the parent drug, sodium sulfamerazine was used in aqueous solution of $0.3 \%$ and distilled water for the purpose of dispersing the permeated drug. The choice of the parent drug was based on its solubility in water, $\mathrm{pH}$ in solution and light absorbent properties in ultraviolet regions. ${ }^{40}$

Permeation of the parent drug was followed up by absorption spectroscopy at $260 \mathrm{~nm}$. First, $2.5 \mathrm{~mL}$ was retrieved from the permeated medium every $10 \mathrm{~min}$, analyzed and returned to its original compartment. Thus, absorbance graphs versus time were constructed with angular coefficients $(\alpha)$ of the curves being utilized for calculating the permeability of the films (P), according to equation 3:

$\mathrm{P}=\alpha \mathrm{VL} / \mathrm{C}_{1} \varepsilon b \mathrm{~S}$

where: $\alpha$ is the straight angular coefficient, $\mathrm{V}$ is the volume of the solution used $(230 \mathrm{~mL}), \mathrm{L}$ is the film thickness, $\mathrm{C}_{1}$ the initial solution concentration, $\varepsilon$ is the coefficient of extinction of the sulfamerazine, $b$ is density of the cuvette, and $\mathrm{S}$ is the area of the film.

The calculation is based on that described by Crank ${ }^{38}$ for the diffusion through the membranes. This method has been cited in the literature ${ }^{41-44}$ for calculating dissolutionpermeation studies of a mefenamic acid nanosuspension, permeability of dimethyl disulfide, permeation of isoniazid and amitriptyline in chitosan membranes and salicylic acid through skim natural rubber films.

\section{Results and Discussion}

\section{Ferrous ion chelating assay}

The polymers isolated from the Agaricus brasiliensis mushroom presented about $96.5 \%$ of the ferrous ion chelation at concentrations of $1.0,2.0$ and $3.0 \mathrm{mg} \mathrm{mL}^{-1}$. These results were similar to those observed for EDTA, the standard used, indicating its antioxidant properties (Figure 1). Studies have shown that polysaccharides obtained from plants and fungi have demonstrated antioxidant activity, which may be justified by the presence of hydroxyl groups capable of stabilizing solitary electrons. $^{45}$

On the other hand, the inhibition of reactive oxygen/ nitrogen species (ROS/RNS) is intrinsically related to the healing process, since the release of these species is increased during the inflammatory process, which 


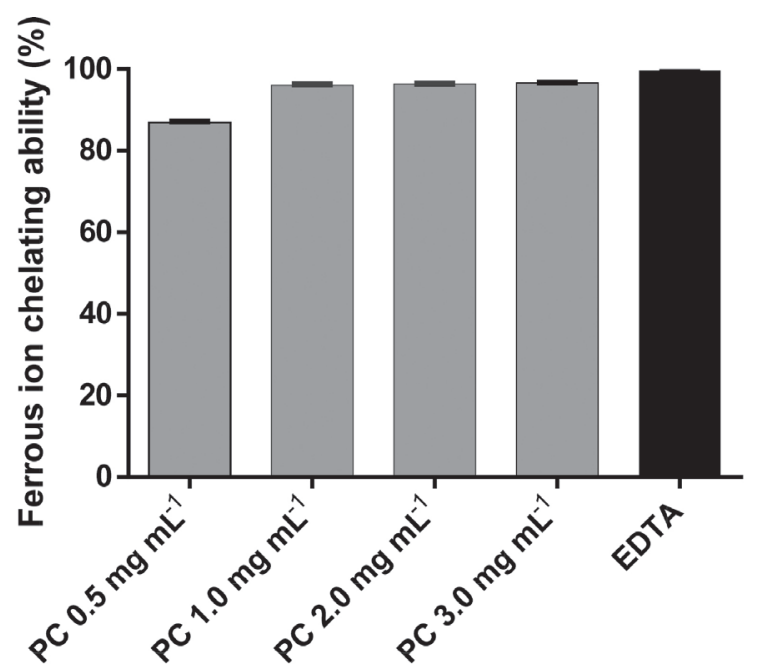

Figure 1. Evaluation of the chelating ability of the ferrous ion by the polysaccharides isolated from the Agaricus brasiliensis mushroom in different concentrations.

corroborates for the occurrence of tissue lesions. Thus, the use of antioxidant substances minimizes the generated damage and guarantees a conducive environment to healing. ${ }^{46-49}$

It is reported in the literature ${ }^{50}$ that polysaccharides isolated from Agaricus brasiliensis mushrooms were able to reduce tissue expression of mRNA (messenger ribonucleic acid) of the proinflammatory cytokine IL- $1 \beta$ in burns, favoring the repair process of injured tissue.

Thereby, it is estimated that the obtained formulations have potential for treating skin lesions since the reduction of inflammation and oxidative stress are important pathways that favor the healing process. ${ }^{46,47}$

\section{Cytotoxicity study}

Lactate dehydrogenase (LDH) is a cytoplasmic enzyme present in all cells of the human body, being rapidly released when the plasma membranes are damaged. Therefore, it is a viable alternative for evaluating the cytotoxicity of systems for biomedical applications. ${ }^{51}$ Figure 2 shows that the activity of the LDH enzyme was not significantly altered by the presence of the polysaccharide at the concentrations used $\left(1.0,10.0,50.0\right.$ and $\left.100.0 \mu \mathrm{g} \mathrm{mL}^{-1}\right)$, whereas the treatment of cells with Triton X-100 (cytotoxic pattern) significantly increased the LDH activity. In addition, studies on cytotoxicity and biocompatibility of chitosan-containing systems have already been reported in the literature, ${ }^{52,53}$ which ensures their safety in biomedical applications. These results show the low toxicity of the polymers used to obtain the films, which guarantees a desirable degree of safety for applications on skin surface.

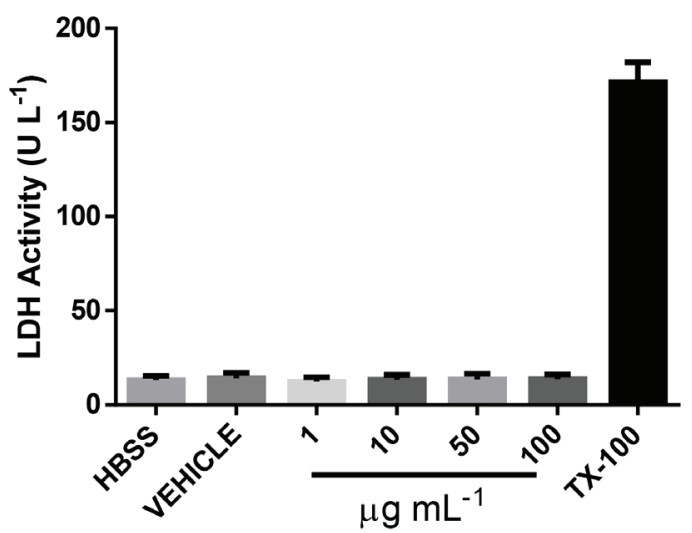

Figure 2. Determination of the cytotoxicity of polysaccharides isolated from the Agaricus brasiliensis mushroom in different concentrations by LDH activity in human neutrophils.

\section{Film characterization}

\section{Thickness and solubility}

The films were prepared with thickness varying from 13 to $28 \mu \mathrm{m}$. In the solubility test they proved to be insoluble in water, basic medium ( $3 \% \mathrm{NaOH}$ solution), ethanol and acetone, but soluble in acidic medium $\left(1 \% \mathrm{CH}_{3} \mathrm{COOH}\right.$ solution). Considering that the substances were solubilized in $1 \%$ acetic acid for the preparation of the films, the solubility of the films in this medium revealed no formation of blending between the polymers, with electrostatic interactions probably occurring between them. The insolubility in ethanol and acetone is a satisfactory aspect regarding the perspective of applying the films in the separation of miscible mixtures, such as with water/ethanol in pervaporation systems..$^{54,55}$

\section{Swelling procedures}

The evaluation of the swelling capacity in water monitored by the variation in the thickness of the dry films after $12 \mathrm{~h}$ of swelling revealed reduced hydrophobicity of the chitosan film with the presence of mushroom polysaccharides (PC). In a specific mode, the swelling capacity of the films decreased with the increase of the polysaccharides concentration (PC). These results are demonstrated in Table 1.

Table 1. Measurements of the thickness of the films before (dry film) and after $12 \mathrm{~h}$ immersion in water (swelling film)

\begin{tabular}{lccc}
\hline Film & Dry film / $\mu \mathrm{m}$ & $\begin{array}{c}\text { Swelling of the } \\
\text { films / } \mu \mathrm{m}\end{array}$ & $\begin{array}{c}\text { Differences in } \\
\text { thickness / } \mu \mathrm{m}\end{array}$ \\
\hline Qt & $28.1 \pm 3.3$ & $41.0 \pm 2.2$ & 13.0 \\
PC/Qt 1:3 & $12.7 \pm 1.3$ & $14.0 \pm 1.6$ & 1.3 \\
PC/Qt 1:5 & $12.9 \pm 1.1$ & $14.9 \pm 1.6$ & 2.0 \\
PC/Qt 1:7 & $21.1 \pm 3.1$ & $32.0 \pm 2.6$ & 10.9 \\
\hline
\end{tabular}

Qt: chitosan; PC: proteoglycans. 
As can be observed, the contents of the water swelled in the films reduced with the increase of PC presence, regardless of the thickness of the films. The reduced swelling of the films with the increase in the PC looks to be a consequence of the closing of the polymeric net mesh, probably due to the electrostatic interactions between the substances.

The results point to the possibility of film swelling control varying with the proportion of polymers. This observation is important considering the perspective of using the films in implants, matrices for controlled liberation of drugs and permeable films. ${ }^{56-58}$

Infrared spectroscopy

The structural characterization of polysaccharides isolated from Agaricus brasiliensis mushroom was reported by Gonzaga et al..$^{14}$ The broad and strong band located between 3490 and $3256 \mathrm{~cm}^{-1}$ in the FTIR spectrum is attributed to the axial stretching of the $\mathrm{O}-\mathrm{H}$ and $\mathrm{N}-\mathrm{H}$ bonds present in the polysaccharides. At $2876 \mathrm{~cm}^{-1}$ there is a narrow band that refers to the symmetric and asymmetric axial stretching of the $\mathrm{C}-\mathrm{H}$ bond relative to the methylene groups.

The presence of the carboxylic acid group of the mushroom proteoglycans was evidenced by the bands present at 1654 and $1419 \mathrm{~cm}^{-1}$, which refer to the symmetric and asymmetric stretches of the carboxylate groups, respectively. Amide group absorbances refer to amino acid residues associated with the structure of the isolated mushroom glucans, as well as the chitosan used, since it has a deacetylation degree of $85.81 \%$.

The band located at $1376 \mathrm{~cm}^{-1}$ refers to the symmetrical folding of the $\mathrm{C}-\mathrm{H}$ bond of the methyl groups $\left(\delta_{\mathrm{s}} \mathrm{C}-\mathrm{H}\right)$. The spectral region between 1155 and $1020 \mathrm{~cm}^{-1}$ shows the glycosidic bonds between the monomers of the polysaccharides, as well as the presence of the anomeric carbon and $\mathrm{C}-\mathrm{O}$ bond stretch, being typical assignments of polysaccharides.

In regard the chemical groups, the structures of both polymers differ in the presence of amine $\left(-\mathrm{NH}_{2}\right)$ and acetamide $\left(-\mathrm{NHCOCH}_{3}\right)$ groups in chitosan, whereas proteoglycans complexes have carboxylic acid $(-\mathrm{COOH})$ groups. The absence of new strips and the preservation of already existing one suggest that, if there is interaction between the mushroom polysaccharides and the chitosan, these are probably electrostatic, with the possibility of attraction between the $-\mathrm{NH}_{3}{ }^{+}$groups of $\mathrm{Qt}$ and $-\mathrm{COO}^{-}$ of PC. Similar behaviors to those which have no bonds were also cited for films constituted of chitosan/pectin and chitosan/sodium alginate. ${ }^{59,60}$ Table 2 shows the main assignments made for Qt, PC, PC/Qt 1:3, PC/Qt 1:5,
PC/Qt 1:7 films according to the FTIR spectrum present in Figure 3.

Table 2. Assignments of the functional groups of the infrared spectra of the prepared films

\begin{tabular}{lc}
\hline Wavenumber $/ \mathrm{cm}^{-1}$ & Assignment \\
\hline $3256-3490$ & $v \mathrm{~N}-\mathrm{H}$ and $v \mathrm{O}-\mathrm{H}$ \\
2876 & $\nu \mathrm{C}-\mathrm{H}$ \\
1654 & $\nu \mathrm{C}=\mathrm{O}$ (amide-I) and $v_{\mathrm{as}} \mathrm{COO}^{-}$ \\
1585 & $\delta \mathrm{N}-\mathrm{H}$ (amide-II) of $-\mathrm{NH}_{2}$ \\
1419 & $v_{\mathrm{s}} \mathrm{COO}^{-}$ \\
1376 & $\delta_{\mathrm{s}} \mathrm{C}-\mathrm{H}$ of $\mathrm{CH}_{3}$ \\
1320 & $\delta \mathrm{CO}-\mathrm{NH}$ and $\mathrm{CH}_{2}($ amide-III) \\
$1020-1155$ & $\nu \mathrm{C}-\mathrm{O}, \mathrm{C}-\mathrm{O}-\mathrm{C}$ and $\mathrm{C} 1-\mathrm{H}$ (anomeric carbon) \\
899 & amide-IV \\
665 & amide- $\mathrm{V}$ \\
\hline
\end{tabular}

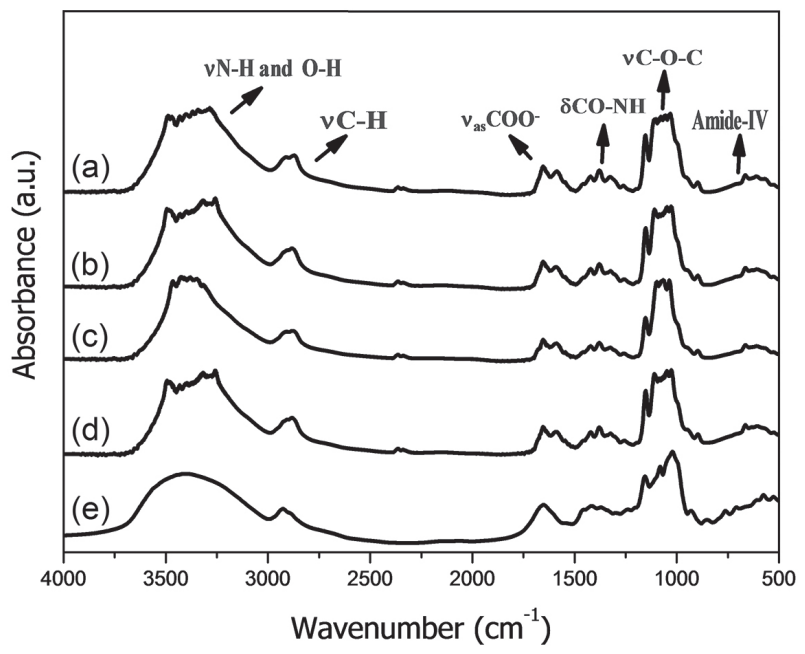

Figure 3. Infrared spectra (ATR) of the films: (a) Qt; (b) PC/Qt 1:3; (c) PC/Qt 1:5; (d) PC/Qt 1:7 and (e) PC.

\section{X-ray diffraction}

The diffractograms of the five films that were prepared are presented in Figure 4. The diffraction curve obtained for the chitosan presented 3 peaks, registered at $10.69,15.04$ and $20.20^{\circ}$. The diffraction peaks at 10.69 and $20.20^{\circ}$ are characteristics of its hydrated crystal structure. ${ }^{61}$ The peak at $15^{\circ}$ is not common in chitosan diffractograms, although it has already been cited as an occurrence in the presence of interlaced anhydrous crystals. ${ }^{62-64}$

Chitosan is considered to be a semi-crystalline polymer, whose crystalline degree is related with its acetylating level, meaning that the less acetylated it is, the more ordered the polymer's structure and more crystalline it will be ${ }^{65}$ The mushroom polysaccharide revealed a peak of around $11.40^{\circ}$ in a diffractogram typical of an amorphous sample. 


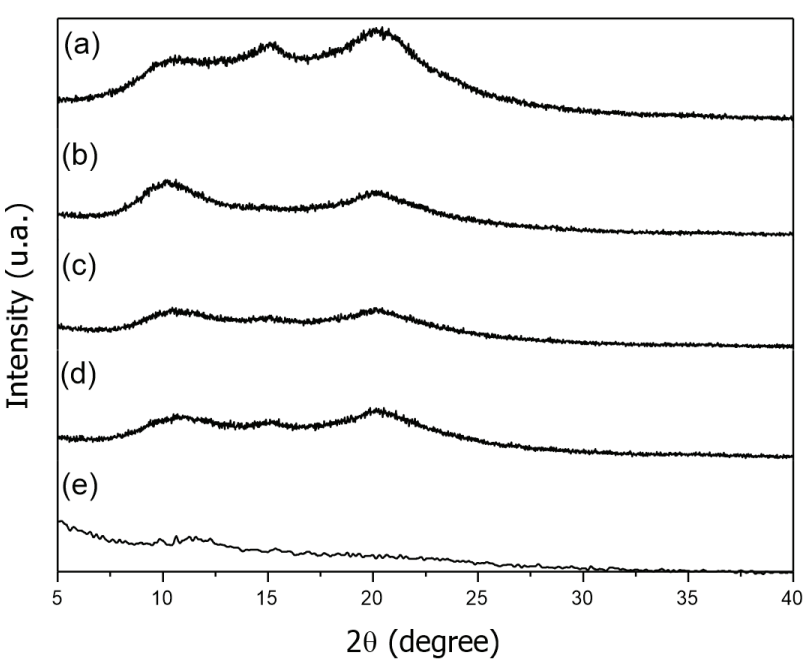

Figure 4. Diffractograms of the systems: (a) Qt film; (b) PC/Qt 1:3 film; (c) PC/Qt 1:5 film; (d) PC/Qt 1:7 film and (e) powder polysaccharide.

Three records of diffraction were observed in the PC/ Qt films. The first was registered at around 10.24, 10.53 and $10.63^{\circ}$ in the PC/Qt 1:3, 1:5 and 1:7 films, respectively, presenting it as having the peak with largest variation of $2 \theta$ in relation to the peak referred to in the chitosan diffractogram. This peak is better shown in the PC/Qt films compared to the chitosan films, probably due to the contribution of the diffraction intensity of the two substances. The second peak was registered between 15.04 and $15.08^{\circ}$ and presented reduced intensity in the PC/Qt films in relation to the Qt film result. This reduction was more strikingly observed in the PC/Qt 1:3 film diffractogram, where there is a greater proportion of the polysaccharide (PC) in the film. The third and final diffraction peak in the PC/Qt films, shown between 20.07 and $20.11^{\circ}$, demonstrated to be better defined in relation to its own chitosan result as the concentration of chitosan was increased. The amorphous character in the $\mathrm{PC} / \mathrm{Qt}$ films are proportionally more pronounced due to the presence of the PC.

\section{Scanning electron microscopy (SEM)}

It was possible to observe alterations in the morphology of the chitosan film surface with the addition of the mushroom polysaccharide by using an electronic microscope. The micrographs for all the studied films are presented in Figure 5.

The analysis shows that the presence of the PC polysaccharides in the PC/Qt films results in denser and uniform microstructures. From the micrograph, it can be verified that the films had a smooth structure, are homogeneous and compact, with similar results being obtained by other authors. ${ }^{66,67}$ On the other hand, the morphology of the films was clearly shown in microscopy micrographs, as well as for chitosan/carboxymethyl chitosan and pectin/chitosan films. ${ }^{68,69}$

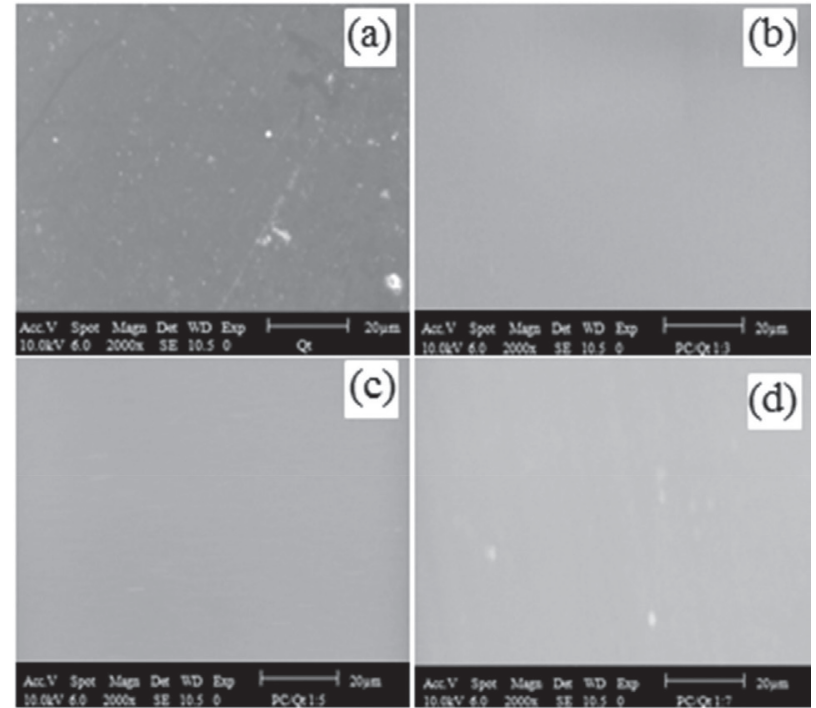

Figure 5. Micrographs of the films: (a) Qt; (b) PC/Qt 1:3; (c) PC/Qt 1:5 and (d) PC/Qt 1:7.

The results from the SEM analysis reinforce the behavior presented in the swelling and permeation tests. The increased concentration of polysaccharides isolated from the mushroom in the composition of the polymeric films corroborates the reduction of swelling and permeability coefficient.

Furthermore, the micrographs show that the increase of PC in PC/Qt films is associated to the increase of the uniformity of the films, since there is an increase in the roughness of the films with the decrease of PC. Similar results were obtained by another author ${ }^{70}$ for films obtained from blends between chitosan-poly(vinyl acetate) (PVA), observing an increase of rough areas with increasing chitosan concentration in the formulations.

\section{Drug permeation procedures}

Polymeric films are often used to evaluate transdermal drug delivery because they provide controllable experimental conditions and do not require the use of animal skin. ${ }^{71,72}$ Therefore, the sodium sulfamerazine permeation assay was performed using the apparatus shown in Figure 6. The permeability coefficient $(\mathrm{P})$ values obtained are presented in Table 3.

The results show changes in the drug permeation of the Qt film with the presence of PC. The data also reveals that the increase of the $\mathrm{PC}$ concentration in the $\mathrm{PC} / \mathrm{Qt}$ compositions reduces the permeation, which can be justified by the probable electrostatic interactions between the $-\mathrm{NH}_{3}{ }^{+}$groups of $\mathrm{Qt}$ and $-\mathrm{COO}^{-}$of $\mathrm{PC}$, evidenced in the infrared spectrum.

In addition, the behavior of the PC/Qt 1:7 film was already expected, since the permeation results are related to the swelling of the films, as the larger the swelling 


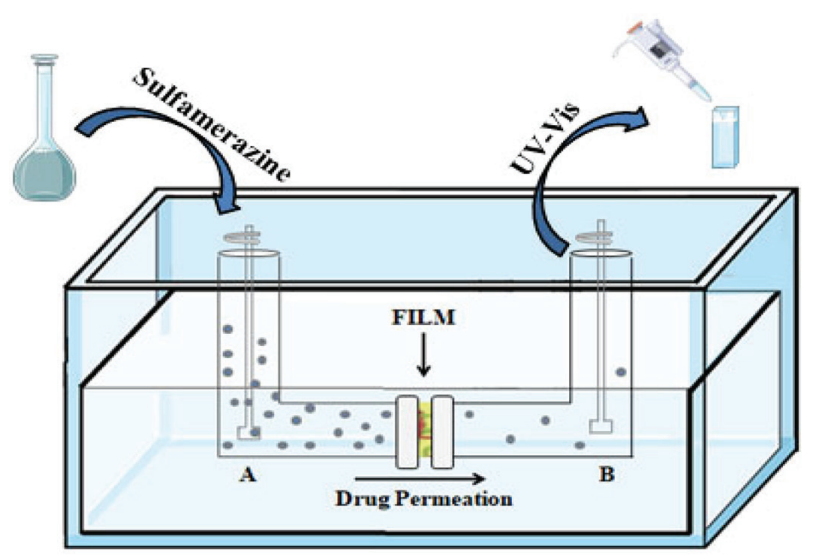

Figure 6. Drug permeation apparatus.

Table 3. Permeability coefficient (P) of the Qt film, PC/Qt 1:3, PC/Qt 1:5 and PC/Qt 1:7 films for sodium sulfamerazine

\begin{tabular}{lc}
\hline Film & $\mathrm{P} \times 10^{5} /\left(\mathrm{cm}^{2} \mathrm{~min}^{-1}\right)$ \\
\hline Qt & 1.40 \\
PC/Qt 1:3 & 0.67 \\
PC/Qt 1:5 & 0.77 \\
PC/Qt 1:7 & 1.29 \\
\hline
\end{tabular}

Qt: chitosan; PC: proteoglycans.

capacity, the greater the permeation. ${ }^{53}$ This fact is related to the polymer chain opening and, consequently, the increase in the pores present in the films.

In parallel, the literature ${ }^{73}$ shows a dependence between thickness and porosity of polypyrrole and dodecyl sulfate films. Thus, the film thicknesses must be considered, as they indirectly influence the permeability coefficient. On the other hand, as the polymers used in the composition of the films are hygroscopic, swelling occurs in the aqueous medium, leading to an increase in thickness and consequent increase in sulfamerazine permeation.

In addition, it is estimated that films with different $P C / Q t$ ratios have a lower permeability coefficient compared to the Qt only film, which provides a delayed permeation, which makes it possible to use drugs with pathway transdermal therapeutic index, giving greater patient safety. ${ }^{74}$

\section{Conclusions}

The significant in vitro antioxidant activity and the results obtained in the cytotoxicity assays demonstrated that polysaccharides isolated from Agaricus brasiliensis mushroom may be used in biomedical applications, including the healing of wounds and burns. The compactness revealed by the micrographs reinforces the idea of the polymeric net mesh progressively closing with the increasing addition of polysaccharide. The infrared region and X-ray diffraction analyses point to the existence of purely electrostatic interaction between the polymers. In addition, the films analysis demonstrated that, with the increase of the polysaccharide concentration of the mushroom in the films, the swelling capacity and permeability of the drug sulfamerazine tends to decrease. Therefore, the amount of proteoglycan present in the films will allow the adjustment in the desired properties for wound care.

\section{Acknowledgments}

This study was financed in part by the Coordenação de Aperfeiçoamento de Pessoal de Nível Superior, Brasil (CAPES), finance code 001 and the Conselho Nacional de Desenvolvimento Científico e Tecnológico (CNPq). The authors also thank CNPq for the grant (N. M. P. S. R., No. 307837/2017-3), the financial support from MCTI/CNPq/ Universal (M. E. N. P. R., No. 424179/2016-4), Central Analítica-UFC/CT-INFRA/MCTI-SISNANO/CAPES for the support and Laboratório de Raios-X/UFC (LRX).

\section{Author Contributions}

Maria L. C. Gonzaga was responsible for the conceptualization, data curation, formal analysis, investigation, methodology, writing: original draft; Matheus. S. Campelo for the data curation, formal analysis, methodology, writing: review and editing; Katarina B. Saraiva for the data curation, formal analysis, methodology, writing: review and editing; Alan Q. S. Santos for the data curation, formal analysis, methodology; Luzia K. A. M. Leal for the formal analysis, methodology, supervision, writing: review and editing; Nágila M. P. S. Ricardo for the funding acquisition, investigation, resources, supervision, writing: original draft, review and editing; Sandra A. Soares for the conceptualization, investigation, writing: original draft; Maria Elenir N. P. Ribeiro for the conceptualization, funding acquisition, investigation, project administration, resources, supervision, writing: original draft, review and editing.

\section{References}

1. Batista, R. A.; Espitia, P. J. P.; Quintans, J. S. S.; Freitas, M. M.; Cerqueira, M. Â.; Teixeira, J. A.; Cardoso, J. C.; Carbohydr. Polym. 2019, 205, 106.

2. Berce, C.; Muresan, M.-S.; Soritau, O.; Petrushev, B.; Tefas, L.; Rigo, I.; Ungureanu, G.; Catoi, C.; Irimie, A.; Tomuleasa, C.; Colloids Surf., B 2018, 163, 155.

3. Voss, G. T.; Gularte, M. S.; Vogt, A. G.; Giongo, J. L.; Vaucher, R. A.; Echenique, J. V. Z.; Soares, M. P.; Luchese, C.; Wilhelm, E. A.; Fajardo, A. R.; Int. J. Pharm. 2018, 552, 340. 
4. Hammami, N.; Gara, A. B.; Bargougui, K.; Ayedi, H.; Abdalleh, F. B.; Belghith, K.; Int. J. Biol. Macromol. 2018, 120, 2123.

5. Kungel, P. T. A. N.; Correa, V. G.; Corrêa, R. C. G.; Peralta, R. A.; Soković, M.; Calhelha, R. C.; Bracht, A.; Ferreira, I. C. F. R.; Peralta, R. M.; Int. J. Biol. Macromol. 2018, 114, 1161.

6. Ahmed, R.; Tariq, M.; Ali, I.; Asghar, R.; Khanam, P. N.; Augustine, R.; Hasan, A.; Int. J. Biol. Macromol. 2018, 120, 385.

7. Moraes, A. F.; Moreira Filho, R. N. F.; Passos, C. C. O.; Cunha, A. P.; Silva, L. M. A.; Freitas, L. B. N.; Vasconcelos, N. F.; Ricardo, N. M. P. S.; Canuto, K. M.; Rosa, M. F.; Leal, L. K. A. M.; Vieira, R. S.; J. Appl. Polym. Sci. 2019, 136, 47128.

8. Ryu, J. H.; Han, N. K.; Lee, J. S.; Jeong, Y. G.; Carbohydr. Polym. 2019, 211, 84.

9. Safdar, R.; Omar, A. A.; Arunagiri, A.; Regupathi, I.; Thanabalan, M.; J. Drug Delivery Sci. Technol. 2019, 49, 642.

10. Hamedi, H.; Moradi, S.; Hudson, S. M.; Tonelli, A. E.; Carbohydr. Polym. 2018, 199, 445.

11. Antony, R.; Arun, T.; Manickam, S. T. D.; Int. J. Biol. Macromol. 2019, 129, 615.

12. Felfel, R. M.; Gideon-Adeniyi, M. J.; Hossain, K. M. Z.; Roberts, G. A. F.; Grant, D. M.; Carbohydr. Polym. 2019, 204, 59.

13. Michailidou, G.; Christodoulou, E.; Nanaki, S.; Barmpalexis, P.; Karavas, E.; Vergkizi-Nikolakaki, S.; Bikiaris, D.; Carbohydr. Polym. 2019, 208, 1.

14. Gonzaga, M. L. C.; Menezes, T. M. F.; de Souza, J. R. R.; Ricardo, N. M. P. S.; Soares, S. A.; Bioact. Carbohydr. Diet. Fibre 2013, 2, 152.

15. Gonzaga, M. L. C.; Menezes, T. M. F.; de Souza, J. R. R.; Ricardo, N. M. P. S.; Freitas, A. L. P.; Soares, S. A.; Int. J. Carbohydr. Chem. 2013, 2013, DOI 10.1155/2013/846565.

16. Yamamoto, K. A.; Galhardi, L. C. F.; Rincão, V. P.; Soares, S. A.; Vieira, Í. G. P.; Ricardo, N. M. P. S.; Nozawa, C.; Linhares, R. E. C.; Int. J. Biol. Macromol. 2013, 52, 9.

17. Smiderle, F. R.; Alquini, G.; Tadra-Sfeir, M. Z.; Iacomini, M.; Wichers, H. J.; Van Griensven, L. J. L. D.; Carbohydr. Polym. 2013, 94, 91.

18. Cardozo, F. T. G. S.; Camelini, C. M.; Cordeiro, M. N. S.; Mascarello, A.; Malagoli, B. G.; Larsen, I. v.; Rossi, M. J.; Nunes, R. J.; Braga, F. C.; Brandt, C. R.; Simões, C. M. O.; Int. J. Biol. Macromol. 2013, 57, 265.

19. Benbettaïeb, N.; Karbowiak, T.; Brachais, C.-H.; Debeaufort, F.; Eur. Polym. J. 2015, 67, 113.

20. Caridade, S. G.; Monge, C.; Gilde, F.; Boudou, T.; Mano, J. F.; Picart, C.; Biomacromolecules 2013, 14, 1653.

21. Liu, G.; Jiang, Z.; Chen, C.; Hou, L.; Gao, B.; Yang, H.; Wu, H.; Pan, F.; Zhang, P.; Cao, X.; J. Membr. Sci. 2017, 537, 229.

22. Xu, L.; Zhang, H.; Wang, L.; Lu, Y.; An, L.; Shi, T.; Polymer 2019, 171, 115 .
23. Staszel, C.; Sinha-Ray, S.; Yarin, A. L.; Pourdeyhimi, B.; Polymer 2017, 112, 92.

24. Kawaguchi, M.; Adv. Colloid Interface Sci. 2017, 247, 163.

25. K., R.; G., B.; Banat, F.; Show, P. L.; Cocoletzi, H. H.; Int. J. Biol. Macromol. 2019, 126, 1234.

26. Aguiar, A. E.; Silva, M. O.; Rodas, A. C. D.; Bertran, C. A.; Carbohydr. Polym. 2019, 207, 480.

27. Kerai, L. V.; Bardés, J.; Hilton, S.; Murdan, S.; Eur. J. Pharm. Sci. 2018, 123, 217.

28. Li, Z.; Lin, S.; An, S.; Liu, L.; Hu, Y.; Wan, L.; Int. J. Biol. Macromol. 2019, 131, 420.

29. Cazón, P.; Vázquez, M.; Velazquez, G.; Int. J. Biol. Macromol. 2018, 117, 235.

30. Devi, N.; Dutta, J.; Int. J. Biol. Macromol. 2019, 127, 222.

31. Liu, X.; You, L.; Tarafder, S.; Zou, L.; Fang, Z.; Chen, J.; Lee, C. H.; Zhang, Q.; Chem. Eng. J. 2019, 359, 1111.

32. Ramasamy, P.; Shanmugam, A.; Int. J. Biol. Macromol. 2015, $74,93$.

33. Gonzaga, M. L. C.; Ricardo, N. M. P. S.; Heatley, F.; Soares, S. A.; Carbohydr. Polym. 2005, 60, 43.

34. Chew, Y. L.; Lim, Y. Y.; Omar, M.; Khoo, K. S.; LWT - Food Sci. Technol. 2008, 41, 1067.

35. Lucisano, Y. M.; Mantovani, B.; J. Immunol. 1984, 132, 2015.

36. Kabeya, L. M.; Kanashiro, A.; Azzolini, A. E.; Soriani, F. M.; Lopes, J. L.; Lucisano-Valim, Y. M.; Res. Commun. Mol. Pathol. Pharmacol. 2002, 111, 103.

37. Mi, Z.; Liu, Z.; Yao, J.; Wang, C.; Zhou, C.; Wang, D.; Zhao, X.; Zhou, H.; Zhang, Y.; Chen, C.; Polym. Degrad. Stab. 2018, 151,80 .

38. Crank, J.; The Mathematics of Diffusion, $2^{\text {nd }}$ ed.; Oxford University Press: London, 1975.

39. Feldman, D.; Polymer Permeability, $1^{\text {st }}$ ed.; Elsevier: London, 1985.

40. Neto, C. G. T.; Dantas, T. N. C.; Fonseca, J. L. C.; Pereira, M. R; Carbohydr. Res. 2005, 340, 2630.

41. Imono, M.; Uchiyama, H.; Ueda, H.; Kadota, K.; Tozuka, Y.; Int. J. Pharm. 2019, 558, 242.

42. Wang, X.; Fang, W.; Yan, D.; Han, D.; Liu, J.; Ren, Z.; Ouyang, C.; Li, Y.; Wang, Q.; Cao, A.; J. Environ. Manage. 2019, 236, 687.

43. Rocha, A. N.; Dantas, T. N.; Fonseca, J. L.; Pereira, M. R.; J. Appl. Polym. Sci. 2002, 84, 44.

44. Danwanichakul, P.; Than-ardna, B.; Ind. Crops Prod. 2018, 122, 166.

45. Pu, X.; Fan, W.; Yu, S.; Li, Y.; Ma, X.; Liu, L.; Ren, J.; Zhang, W.; Can. J. Physiol. Pharmacol. 2015, 93, 39.

46. Shao, Y.; Dang, M.; Lin, Y.; Xue, F.; Life Sci. 2019, 231, 116422.

47. Chen, J.; Jayachandran, M.; Xu, B.; Yu, Z.; J. Ethnopharmacol. 2019, 236, 263. 
48. Sellimi, S.; Maalej, H.; Rekik, D. M.; Benslima, A.; Ksouda, G.; Hamdi, M.; Sahnoun, Z.; Li, S.; Nasri, M.; Hajji, M.; Int. J. Biol. Macromol. 2018, 119, 633.

49. Tümen, İ.; Akkol, E. K.; Taştan, H.; Süntar, I.; Kurtca, M.; J. Ethnopharmacol. 2018, 211, 235.

50. Sui, Z.; Yang, R.; Liu, B.; Gu, T.; Zhao, Z.; Shi, D.; Chang, D.; Int. J. Biol. Macromol. 2010, 47, 155.

51. Korzeniewski, C.; Callewaert, D. M.; J. Immunol. Methods 1983, 64, 313.

52. Javaid, M. A.; Zia, K. M.; Khera, R. A.; Jabeen, S.; Mumtaz, I.; Younis, M. A.; Shoaib, M.; Bhatti, I. A.; Int. J. Biol. Macromol. 2019, 129, 116 .

53. Tyliszczak, B.; Drabczyk, A.; Kudłacik-Kramarczyk, S.; Bialik-Wąs, K.; Kijkowska, R.; Sobczak-Kupiec, A.; Colloids Surf., B 2017, 160, 325.

54. Castro-Muñoz, R.; J. Food Eng. 2019, 253, 27.

55. Kononova, S. V.; Kruchinina, E. V.; Petrova, V. A.; Baklagina, Y. G.; Klechkovskaya, V. V.; Orekhov, A. S.; Vlasova, E. N.; Popova, E. N.; Gubanova, G. N.; Skorik, Y. A.; Carbohydr. Polym. 2019, 209, 10.

56. Padula, C.; Nicoli, S.; Pescina, S.; Santi, P.; Colloids Surf., B 2019, 174, 582.

57. Yang, L.; An, D.; Wang, T.-J.; Kan, C.; Jin, Y.; Particuology 2017, 30, 73 .

58. Talekar, S. D.; Haware, R. V.; Dave, R. H.; Eur. J. Pharm. Sci. 2019, 130, 215.

59. Gao, H.-X.; He, Z.; Sun, Q.; He, Q.; Zeng, W.-C.; Carbohydr. Polym. 2019, 215, 1.

60. Wang, H.; Gong, X.; Miao, Y.; Guo, X.; Liu, C.; Fan, Y.-Y.; Zhang, J.; Niu, B.; Li, W.; Food Chem. 2019, 283, 397.

61. Qiao, C.; Ma, X.; Zhang, J.; Yao, J.; Carbohydr. Polym. 2019, 206, 602 .
62. Chen, M.; Runge, T.; Wang, L.; Li, R.; Feng, J.; Shu, X.-L.; Shi, Q.-S.; Carbohydr. Polym. 2018, 200, 115.

63. Shipovskaya, A. B.; Shmakov, S. L.; Gegel, N. O.; Carbohydr. Polym. 2019, 206, 476.

64. Lucio, D.; Zornoza, A.; Martínez-Ohárriz, M. C.; Int. J. Pharm. 2014, 467, 19.

65. Zhu, L.-F.; Li, J.-S.; Mai, J.; Chang, M.-W.; Chem. Eng. J. 2019, 357,498 .

66. Zhang, C.; Wang, Z.; Li, Y.; Yang, Y.; Ju, X.; He, R.; Food Chem. 2019, 272, 694.

67. Chylińska, M.; Kaczmarek, H.; Burkowska-But, A.; Colloids Surf., B 2019, 176, 379.

68. Zimet, P.; Mombrú, A. W.; Mombrú, D.; Castro, A.; Villanueva, J. P.; Prado, H.; Rufo, C.; Carbohydr. Polym. 2019, 219, 334.

69. Younis, H. G. R.; Zhao, G.; Int. J. Biol. Macromol. 2019, 131, 1057.

70. Liu, Y.; Wang, S.; Lan, W.; Int. J. Biol. Macromol. 2018, 107, 848.

71. Karadzovska, D.; Riviere, J. E.; Eur. J. Pharm. Sci. 2013, 50, 569.

72. Haq, A.; Dorrani, M.; Goodyear, B.; Joshi, V.; Michniak-Kohn, B.; Int. J. Pharm. 2018, 539, 58.

73. Hallik, A.; Roosalu, K.; Mändar, H.; Joosu, L.; Marandi, M.; Tamm, J.; Eur. Polym. J. 2015, 70, 118.

74. Kim, B.; Seong, K.-Y.; You, I.; Selvaraj, V.; Yim, S.-G.; O'Cearbhaill, E. D.; Jeong, U.; Yang, S. Y.; Sens. Actuators, B 2018, 256, 18.

Submitted: August 18, 2019

Published online: November 25, 2019 